\title{
The genomic expression test EndoPredict is a prognostic tool for identifying risk of local recurrence in postmenopausal endocrine receptor-positive, her2neu-negative breast cancer patients randomised within the prospective ABCSG 8 trial
}

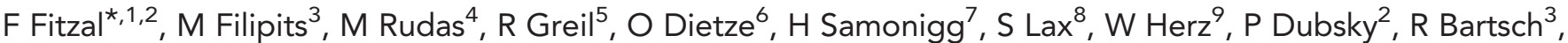
R Kronenwett ${ }^{10}$ and $M$ Gnant $^{2}$ on behalf of the Austrian Breast and Colorectal Cancer Study group (ABCSG) ${ }^{1}$ Hospital of the Sisters of Charity, Breast Health Center, Linz, Austria; ${ }^{2}$ Department of Surgery and Comprehensive Cancer Center, Medical University Vienna, Vienna, Austria; ${ }^{3}$ Department of Oncology, Medical University Vienna, Vienna, Austria; ${ }^{4}$ Department of Pathology, Medical University Vienna, Vienna, Austria; ${ }^{5}$ Department of Oncology, Salzburger Landesklinik, Salzburg, Austria; ${ }^{6}$ Department of Pathology, Salzburger Landesklinik, Salzburg, Austria; ${ }^{7}$ Department of Oncology, Medical University Graz, Graz, Austria; ${ }^{8}$ Department of Pathology, Medical University Graz, Graz, Austria; ${ }^{9}$ Department of Surgery, KH Leoben, Leoben, Austria and ${ }^{10}$ Sividon Diagnostics, Cologne, Germany

Background: The aim of this study was to examine whether EndoPredict (EP), a novel genomic expression test, is effective in predicting local recurrence (LR)-free survival (LRFS) following surgery for breast cancer in postmenopausal women. In addition, we examined whether EP may help tailor local therapy in these patients.

Methods: From January 1996 to June 2004, 3714 postmenopausal patients were randomly assigned to either tamoxifen or tamoxifen followed by anastrozole within the prospective ABCSG 8 trial. Using assay scores from EP, we classified breast tumour blocks as either low or high risk for recurrence.

Results: Data were gathered from 1324 patients. The median follow-up was 72.3 months and the cumulative incidence of LR was $2.6 \%(0.4 \%$ per year). The risk of $L R$ over a 10-year period among patients with high-risk lesions $(n=683)$ was significantly higher (LRFS $=91 \%)$ when compared with patients with low-risk lesions $(n=641)(10-y e a r$ LRFS =97.5\%) (HR: $1.31(1.16-1.48) P<0.005)$. The groups that received breast conservation surgery (BCT) and mastectomy (MX) had similar LR rates $(P=0.879)$. Radiotherapy (RT) after BCT significantly improved LRFS in the cohorts predicted by EP to be low-risk for LR (received RT: $n=436,10$-year LRFS 99.8\%; did not receive RT: $n=63$, 10-year LRFS 83.6\%, $P<0.005)$.

Conclusions: EndoPredict is an effective prognostic tool for predicting LRFS. Among postmenopausal, low-risk patients, EP does not appear to be useful for tailoring local therapy. 
Breast-conserving therapy (BCT) with adjuvant radiotherapy $(\mathrm{RT})$ is a well-established and widely accepted clinical therapeutic alternative to mastectomy (MX) in women with early-stage breast cancer. However, rates of local recurrence (LR) among women with early-stage breast cancer might be higher among patients who received BCT instead of MX (Jatoi and Proschan, 2005 \#2863) There are multiple reasons why it would be clinically relevant to better identify risk for LR: firstly, approximately $65 \%$ of patients with LR eventually develop distant metastases (Tanis et al, 2012 \#2864). In half of these patients, LR was the first clinical event, which supports the notion that predicting LR may help to diagnose patients at risk for distant recurrence at an earlier stage. Moreover, predicting LR may also help in tailoring local therapy. For instance, it may be of clinical importance to recommend MX for high-risk patients instead of BCT in order to reduce the risk of LR. Furthermore, it may be possible to omit RT in low-risk patients if validated tools to predict LR were available. Given the limited resources available to healthcare systems in the current age, it would be particularly advantageous to be able to identify a subgroup of patients who may not benefit from local RT. In addition, this could spare some patient subgroups from undergoing RT unnecessarily.

Classic prognostic factors for LR are age, nodal positivity and tumour size (Voogd et al, 2001 \#2865). The use of immunohistochemical subtype analyses has proven to be effective in identifying tumours at a higher risk for LR (Tibshirani et al, 2002; Millar et al, 2009; Voduc et al, 2010). In this respect, basal-like as well as her2enriched breast cancer patients (as defined by immunohistochemistry) had worse local relapse-free survival (LRFS) compared with luminal subtypes (Kreike et al, 2009; Millar et al, 2009; Voduc et al, 2010; Cancello et al, 2011; Kneubil et al, 2013). The 21-gene recurrence score was the first multigenomic test to suggest that cancer-related genes may indeed predict LR (Mamounas et al, 2010). To date, the implications of this finding in regard to customising local therapy have not been investigated.

The aim of this study was to investigate whether EndoPredict (EP), an RNA-based multigene scoring tool, is effective at predicting distant recurrence (Filipits et al, 2011; Dubsky et al, 2013a) and if it functions as an independent prognostic marker for LRFS. In addition, we set out to examine the role of EP in its potential to tailor local therapy strategies. We hypothesised that MX would reduce risk for LR in breast cancer patients whose EP scores were classified as high risk. In addition, we investigated the hypothesis that RT may be safely omitted in breast cancer patients whose EP scores were classified as low risk.

\section{MATERIALS AND METHODS}

The present investigation is part of the ABCSG translational research program (abcsg.research) and the ABCSG operative therapy program (abcsg.surgery). All samples were taken from patients randomised within the ABCSG trial 8 described above.

Trial design. The Austrian Breast and Colorectal Cancer Study Group (ABCSG) initiated a prospective, randomised trial comparing sequential therapy consisting of tamoxifen followed by anastrozole to tamoxifen alone in postmenopausal endocrineresponsive breast cancer patients (Dubsky et al, 2012). Between January 1996 and June 2004, 3714 patients were enrolled in the study (NCT00291759). The ABCSG additionally randomly assigned 869 women from the ABCSG 8 trial with a low-risk profile (based on tumour size of $<3 \mathrm{~cm}$, nodal status of $\mathrm{pN} 0$ and grading of 1 and 2 only) to a RT-treatment arm or non-RT treatment arm following BCT (Potter et al, 2007). All patients provided written informed consent. In addition, the trial was approved by the respective ethics committees of the trial sites and done in accordance with the Declaration of Helsinki. Formalin- fixed paraffin-embedded tumour blocks of 1324 patients were available for analysis by the genetic expression tool EP. All data from these patients were analysed for this study. EndoPredict has been previously shown to be an independent prognostic marker for distant recurrence (Filipits et al, 2011).

Local therapy. All patients underwent BCT or MX (resection-free margins defined as no tumour cells on ink, or at least $1 \mathrm{~mm}$ of resection-free margin) as well as sentinel lymph node biopsy in cases of clinically and radiologically negative axillary lymph nodes. In cases of macrometastases or micrometastases of the sentinel lymph node, axillary dissection level I and II were performed. MX was performed when positive margins following breast conservation were found and there was no possibility of performing another resection without a deleterious cosmetic outcome, as well as in cases of multicentric breast cancer. All patients received routine RT after BCT with the exception of the aforementioned mentioned patients who were randomised to the non-RT treatment arm (ABCSG 8a). Radiotherapy after MX was done based on the discretion of the trial centres and standard guidelines (e.g., more than 4 positive lymph nodes or 1-3 positive lymph nodes with another risk factor such as young age, L1 or G3).

Monitoring took place every 3 months throughout the first year, at 6-month intervals through the second and third year, and annually thereafter. Gynaecological examinations, thoracic X-rays, skeletal scintigraphy, abdominal ultrasound and mammography were performed to identify the presence of local and distant recurrence as well as overall survival. In some patients, computed tomography of the thorax and the abdomen were also performed to detect distant metastases. Events were confirmed histologically, cytologically or by various radiological screening methods.

EndoPredict (EP). A detailed report of the training process and the EP score is available in the literature (see Filipits et al, 2011). Briefly, the score ranges from 0 to 15 and consists of eight genes of interest that are implicated in carcinogenesis (genes of interest: BIRC5, UBE2C, DHCR7, RBBP8, IL6ST, AZGP1, MGP and STC2) and three normalisation genes (CALM2, OAZ1 and RPL37A). EndoPredict is arranged as a linear combination intended to predict recurrence. Relative expression of each genes of interest was assessed as a delta cycle with threshold values based on normalisation of the average of three reference genes (CALM2, OAZ1 and RPL37A). The EP significantly adds prognostic information to Adjuvant!Online in combination with quantitative ER expression and KI67. EndoPredict has previously been shown to significantly predict distant recurrence-free survival in postmenopausal endocrine-responsive and her2neu-negative breast cancer patients (Filipits et al, 2011).

All FFPE tumour blocks were collected at the time surgery prior to adjuvant therapy. Approval was obtained from institutional review boards. Tumour sections ranging from 4 to 10 micrometres were cut and stained by haematoxylin/eosin to confirm invasive cancer and further sections were used for molecular analyses. Pathologists from participating ABCSG centres sent paraffin blocks to the abcsg.research centre at the Medical University Vienna. In total, 24 centres contributed samples (see acknowledgments). Her2 and KI67 were assayed by IHC and evaluated centrally in the abcsg.research laboratory at the Medical University Vienna (Pohl et al, 2003; Reiner-Concin et al, 2008).

Total RNA was extracted from the FFPE tissue section with a silica-based, fully automated isolation method (Tissue Preparation System, VERSANT Tissue Preparations Reagents, Siemens Healthcare Diagnostics, Tarrytown, NY, USA) as published earlier (Filipits et al, 2011). All samples were analysed with quantitative one-step reverse transcriptase PCR on an ABI PRISM 7900HT (Applied Biosystems, Foster City, CA, USA) using SuperScript III PLATINUM qRT-PCR with ROX (Invitrogen, Grand Island, NY, USA). All PCR assays were conducted in triplicate 
Definition of LR as endpoint. Local recurrence was defined as breast or chest skin recurrence, excluding the regional lymph nodes. Patients with distant metastases prior to LR were excluded for analyses. Patients who developed distant recurrence simultaneously or after LR were included in the analyses.

Statistic analyses. The primary endpoint of this analysis was LRFS, which we define as the time from randomisation to the first occurrence of LR. Baseline data according to dichotomised EP status (low risk, high risk) were compared in univariate analyses using the chi-square test and in a multiple logistic model. Survival rates were estimated with the use of the Kaplan-Meier method. The prognostic value for LR risk of EP was evaluated using univariate and multiple Cox models. All multiple Cox regression models mentioned below were adjusted for age, tumour size, lymph node status, adjuvant endocrine treatment and RT. All reported $P$-values are from twosided tests. A $P$-value equal to or less than $5 \%$ was considered statistically significant. All statistical analyses were performed using IBM SPSS Statistics software, version 21.0 (IBM Corporation, Armonk, NY, USA).

\section{RESULTS}

Demographics. Table 1 shows pathologic and clinical characteristics of all patients in this subset. Genetic expression profiles of the tumour blocks as well as all clinical data from 1324 patients were included in the final analysis. The median age was 63 (ages ranged from 41-80). Fifty-two percent of patients were high risk according to EP and $26 \%$ had nodal positivity. Although all patients were oestrogen receptor-positive, $20 \%$ additionally had negative progesterone-receptor disease. None of the patients had G3 breast cancer and $83 \%$ had BCT. Out of these $83 \%$ patients, $16 \%$ were randomly assigned to not receive RT within the ABCSG $8 \mathrm{a}$ trial.

Local recurrence data. Thirty-five out of 1324 patients $(2.6 \%)$ developed LR within 72.5 months of follow-up. Nineteen LR events were detected within 5 years after surgery (54.3\%). Five of the 35 patients with LR had additional distant metastases (14.3\%). Approximately half of the cases of local and distant recurrence occurred within the first 5 years following breast surgery, whereas the other half occurred after 5 years $(15.8 \%$ before 5 years $v s 12.5 \%$ after 5 years).

EndoPredict as a prognostic test for LR risk. EndoPredict accurately predicted LR-free survival $(P<0.008)$ as outlined in Figure 1. Multivariate analyses using tumour size, nodal status, age and local as well as adjuvant endocrine therapy revealed that EP together with RT are independent prognostic factors for LRFS in this subset (Table 2). Risk of local relapse was 30\% higher in highrisk patients compared with low-risk patients ( 9 out of $641=1.4 \%$ events in EP low-risk; 26 out of $683=3.8 \%$ events in EP high-risk, $P=0.005)$.

Surgical technique and LR risk. This study was limited by a small number of events in each subgroup. From the 35 events observed after 72.3 months follow-up, 29 occurred after BCT and only 6 were observed after MX. Fifteen events occurred in the EP highrisk group, 4 after MX and 11 after BCT (Table 3). We conducted an exploratory statistical analysis to elucidate the value of MX in EP high-risk patients. The risk of developing a LR event after BCT followed by RT $(n=1094)$ was not significantly different compared with $\mathrm{MX}(n=230 ; P=0.357$ data not shown). In an exploratory analysis, there was no significant difference in the risk of LR in EP high-risk patients when comparing $\mathrm{MX}(n=110)$ with BCT followed by RT $(n=475)$ (see Figure 2$)$.

Radiotherapy after BCT and LR risk. RT showed an independent prognostic value for reducing LR (Table 2). The exploratory
Table 1. Patient characteristics

\begin{tabular}{|c|c|c|}
\hline Patient characteristics & $\mathbf{N}$ & $\%$ \\
\hline \multicolumn{3}{|l|}{ Age } \\
\hline Median, years & 63 & \\
\hline Range, years & $41-80$ & \\
\hline$<60$ years & 459 & 34.7 \\
\hline \multicolumn{3}{|l|}{ Tumour stage } \\
\hline T1 & 935 & 70.6 \\
\hline $\mathrm{T} 2$ & 373 & 28.2 \\
\hline T3 & 16 & 1.2 \\
\hline \multicolumn{3}{|l|}{ Nodal status } \\
\hline N0 (no positive nodes) & 937 & 70.8 \\
\hline N1 (1-3 positive nodes) & 350 & 26.4 \\
\hline $\mathrm{N} 2^{\mathrm{a}}$ (4-9 positive nodes) & 37 & 2.8 \\
\hline \multicolumn{3}{|l|}{ Grade } \\
\hline G1 & 288 & 21.8 \\
\hline G2 & 939 & 70.9 \\
\hline GX & 97 & 7.3 \\
\hline \multicolumn{3}{|l|}{ ER status } \\
\hline Low expression & 99 & 7.5 \\
\hline Medium expression & 401 & 30.3 \\
\hline High expression & 824 & 62.2 \\
\hline \multicolumn{3}{|l|}{ PgR status } \\
\hline Negative & 272 & 20.5 \\
\hline Low expression & 217 & 16.4 \\
\hline Medium expression & 452 & 34.1 \\
\hline High expression & 383 & 28.9 \\
\hline \multicolumn{3}{|l|}{ Adjuvant therapy } \\
\hline Tamoxifen only & 651 & 49.2 \\
\hline Tamoxifen/Anastrozole & 673 & 50.8 \\
\hline \multicolumn{3}{|l|}{ Type of surgery } \\
\hline Breast conservation & 1094 & 82.6 \\
\hline Mastectomy & 230 & 17.4 \\
\hline \multicolumn{3}{|l|}{ Radiotherapy $(n=1315)$} \\
\hline Yes & 973 & 74.0 \\
\hline No & 342 & 26.0 \\
\hline \multicolumn{3}{|l|}{ EndoPredict } \\
\hline Low risk & 641 & 48.4 \\
\hline High risk & 683 & 51.6 \\
\hline \multicolumn{3}{|c|}{$\begin{array}{l}\text { Abbreviations: } E R=\text { oestrogen receptor; } \mathrm{PgR}=\text { progesteron receptor. Demographic data } \\
\text { from all patients undergoing breast conservation } \pm \text { radiotherapy or mastectomy followed by } \\
\text { either adjuvant tamoxifen or a tamoxifen/anastrozol sequence during } 5 \text { years. Out of these } \\
\text { postmenopausal clinical low risk patients, } 50 \% \text { of the tumours showed a genetic high-risk } \\
\text { profile for local and distend recurrence. } \\
{ }^{a} \text { One patient with }>9 \text { positive lymph nodes. }\end{array}$} \\
\hline
\end{tabular}

analyses to determine the effectiveness of RT in the EP low-risk subgroup also demonstrated a significant benefit from RT after BCT (see Figure $3(P<0.005)$ ). From the 35 events, only 8 took place in the EP low-risk group after BCT $(n=499)$. Local recurrence-free survival in this subgroup was $98.3 \%$. While only one event was found after BCT and RT $(n=436 ; 0.2 \%)$, there were seven events observed within the group of patients receiving only BCT $(n=63 ; 11.1 \%)$ (see Table 4 ). The high-risk group had a similar benefit from RT $(P<0.005)$, as demonstrated in Table 4.

EPclin and predicting LR. Earlier data showed that the inclusion of clinical risk factors (nodal status and tumour size) improved the prognostic value of the EP score (Dubsky et al, 2013b). Our data show that EPclin compared with EP increased the number of lowrisk patients from 499 to 688 (increase of 27\%) without interfering with the prognostic value of the EP score for LR (see Table 5). RT significantly decreased the number of LR in the EPclin low-risk group (data not shown). 


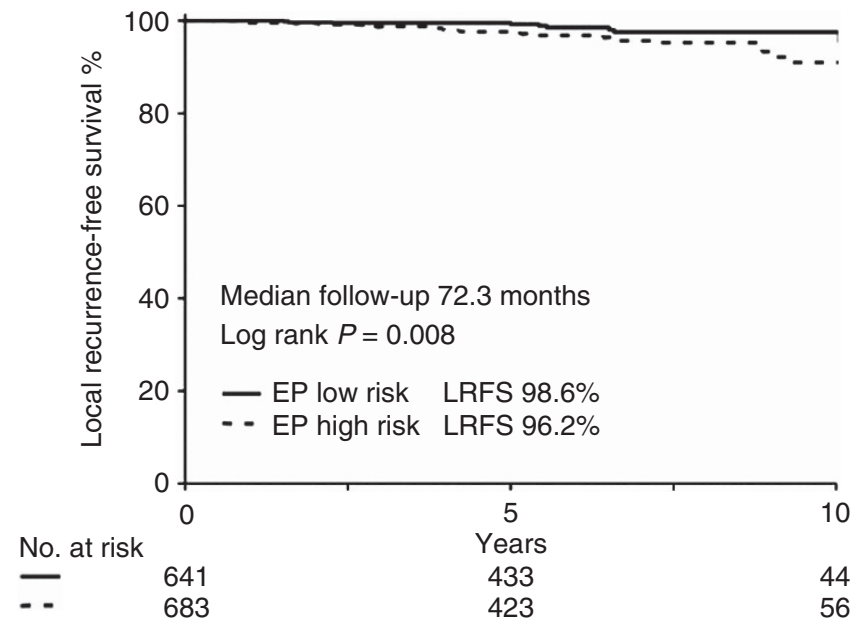

Figure 1. Kaplan-Meier curve of LRFS for patients undergoing $\mathrm{BCT} \pm \mathrm{RT}$ or MX followed by either adjuvant tamoxifen or a tamoxifen/ anastrozole sequence during 5 years. $50 \%$ of all patients had a highrisk cancer lesion measured by EP genetic expression score.

EndoPredict high-risk lesions had a significant higher local recurrence rate $(P=0.008)$.

Table 2. Multivariate COX regression model analysing risk factors for local recurrence-free survival in all patients undergoing breast conservation and radiotherapy or mastectomy followed by either adjuvant tamoxifen or a tamoxifen/anastrozole sequence during 5 years.

\begin{tabular}{|l|c|c|c|c|}
\hline & RR & $\mathbf{2 5 \%}$ & $\mathbf{7 5 \%}$ & $\boldsymbol{P}$ \\
\hline Age & 1010 & 0.968 & 1054 & 0.650 \\
\hline $\mathrm{T}$ & 0.887 & 0.424 & 1857 & 0.750 \\
\hline $\mathrm{N}$ & 0.947 & 0.481 & 1866 & 0.875 \\
\hline endT & 0.700 & 0.348 & 1408 & 0.317 \\
\hline RT & 0.251 & 0.123 & 0.512 & $<\mathbf{0 . 0 0 5}$ \\
\hline EP & 1312 & 1164 & 1478 & $<\mathbf{0 . 0 0 5}$ \\
\hline
\end{tabular}

Abbreviations: endT=endocrine therapy; $E P=$ EndoPredict; $N=$ nodal status; $R T=$ radiotherapy; $\mathrm{T}=$ tumour size. The genetic expression profile analysed by the EndoPredict was an independent prognostic factor for the occurrence of a local recurrence.

Table 3. Local recurrence risk comparing breast conservation with mastectomy in enbdopredict low- and high risk patients.

\begin{tabular}{|l|c|c|c|c|c|}
\hline & $\begin{array}{c}\mathbf{n} \text { low } \\
\text { risk }\end{array}$ & $\begin{array}{c}\text { LR } \\
\text { low-risk }\end{array}$ & $\begin{array}{c}\text { n high } \\
\text { risk }\end{array}$ & $\begin{array}{c}\text { LR } \\
\text { high-risk }\end{array}$ & LR total \\
\hline BCT & 436 & $1(0.2 \%)$ & 475 & $12(2.5 \%)$ & $13(1.4 \%)$ \\
\hline MX & 104 & $1(0.9 \%)$ & 110 & $3(2.7 \%)$ & $4(1.9 \%)$ \\
\hline Total & 540 & $2(0.4 \%)$ & 585 & $15(2.6 \%)$ & $17(1.5 \%)$ \\
\hline $\begin{array}{l}\text { Abbreviations: BCT = breast-conserving therapy; LR = local recurrence; MX = mastectomy; } \\
n=\text { number of patients; RT = radiotherapy. Endopredict high- and low-risk differentiated } \\
\text { between high and low number of LR. No differences in LR between MX and BCT +RT. } \\
\text { Numbers of events are very small. }\end{array}$ \\
\hline
\end{tabular}

\section{DISCUSSION}

This analysis from 1324 tumour blocks of women randomised within a prospective trial with a follow-up of 72.3 months demonstrates that the RNA-based genetic expression tool EP predicts LR independently of age, tumour size and nodal status. In this clinically low- to intermediate-risk group, only $2.6 \%$ developed LR (annual rate of 0.4\%). EndoPredict high-risk patients were at a $30 \%$ increased risk of developing LR compared with EP low-risk patients. Mastectomy did not improve the rates of LR as compared

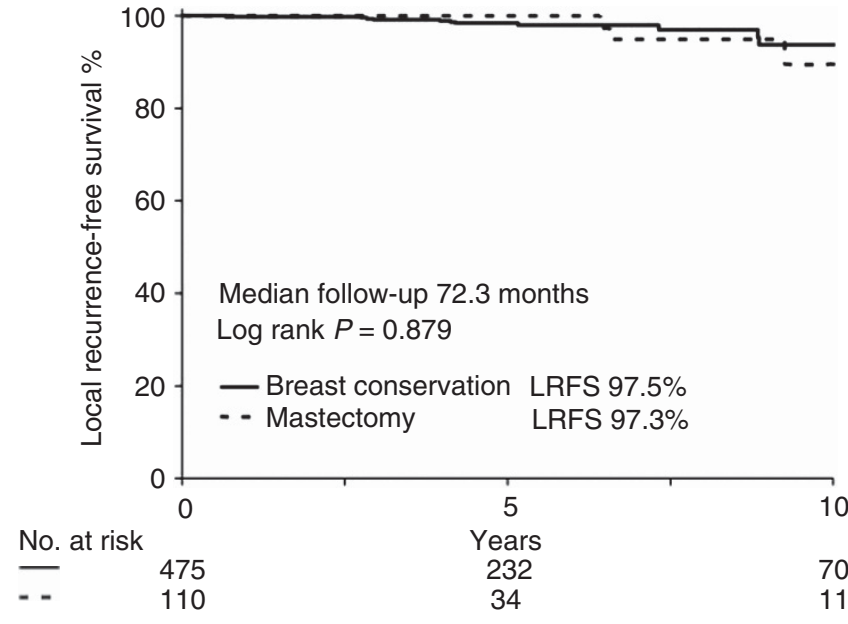

Figure 2. Kaplan-Meier curve of LRFS only for patients with an EP high-risk cancer lesion undergoing BCT with RT or MX followed by either adjuvant tamoxifen or a tamoxifen/anastrozole sequence during 5 years. The increased LRFS in high-risk patients was not improved by $\mathrm{MX}$.

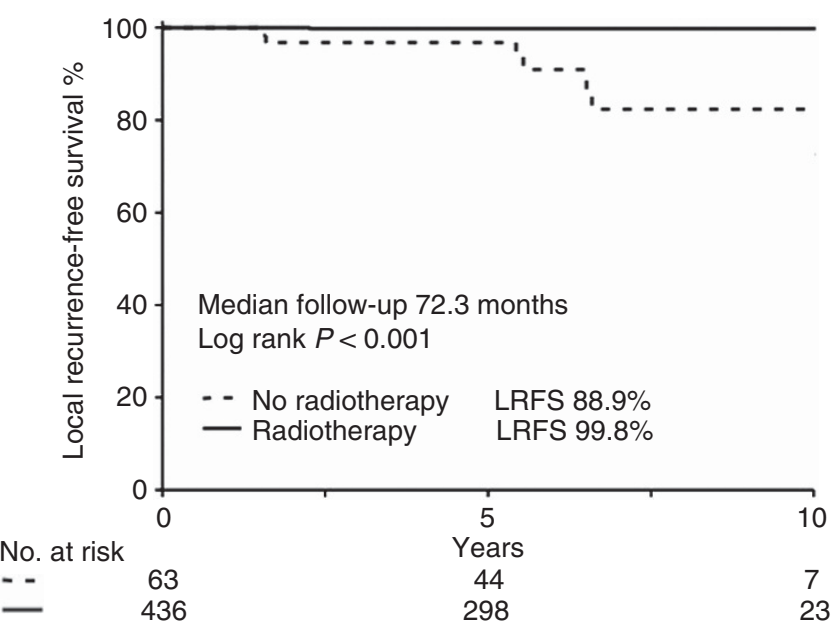

Figure 3. Kaplan-Meier curve of LRFS for EP low-risk patients undergoing $\mathrm{BCT} \pm \mathrm{RT}$ followed by either adjuvant tamoxifen or a tamoxifen/anastrozole sequence during 5 years. Radiotherapy improved LR even in low-risk patients significantly $(P<0.001)$.

Table 4. Local recurrence risk comparing patients after breast conservation with or without radiotherapy.

\begin{tabular}{|l|c|c|c|c|l|}
\hline & $\begin{array}{c}\text { n low } \\
\text { risk }\end{array}$ & $\begin{array}{c}\text { LR } \\
\text { low-risk }\end{array}$ & $\begin{array}{c}\text { n high } \\
\text { risk }\end{array}$ & $\begin{array}{c}\text { LR } \\
\text { high-risk }\end{array}$ & LR total \\
\hline $\mathrm{BCT}-\mathrm{RT}$ & 63 & $7(11.1 \%)$ & 75 & $9(12.0 \%)$ & $16(11.6 \%)$ \\
\hline $\mathrm{BCT}+\mathrm{RT}$ & 436 & $1(0.2 \%)$ & 475 & $12(2.5 \%)$ & $13(1.4 \%)$ \\
\hline Total & 499 & $8(0.4 \%)$ & 550 & $21(3.8 \%)$ & $19(1.8 \%)$ \\
\hline $\begin{array}{l}\text { Abbreviations: } \mathrm{BCT}=\text { breast-conserving therapy; } \mathrm{LR}=\text { local recurrence; } n=\text { number of patients; } \\
\text { RT= radiotherapy. Endopredict high- and low-risk differentiated between high and low } \\
\text { number of } \mathrm{LR} \text {. RT reduced number of } \mathrm{LR} \text { after } \mathrm{BCT} \text {. Numbers of events are very small. }\end{array}$ \\
\hline
\end{tabular}

with BCT in both low-risk and the high-risk patients. The use of adjuvant RT reduced LR rates in both categories, which suggests that the use of EP may not be suitable for tailoring local therapy within clinically defined low-risk patients.

EndoPredict prognosis of LR. This study investigated clinically low- to intermediate-risk breast cancer patients, which we based on 
Table 5. The inclusion of clinical factors to the EP score increased the number of low-risk patients without changing the prognostic significance for LRFS

\begin{tabular}{|l|c|c|c|} 
& $\boldsymbol{n}$ & Events & LRFS\% \\
\hline EP low & 499 & 8 & 98,4 \\
\hline EPclin low & 688 & 12 & 98,3 \\
\hline EP high & 550 & 21 & 96,2 \\
\hline EPclin high & 361 & 17 & 95,3 \\
\hline
\end{tabular}

Abbreviations: $E P=$ EndoPredict; $E P c l i n=$ combines $E P$ with nodal status and tumour size; LRFS = local recurrence-free survival.

immunohistochemical subtype analyses (80\% Luminal A, 20\% Luminal B; not basal like or her2-positive cancers). EndoPredict determined that $52 \%$ of the patients had a high-risk breast cancer lesion. These EP high-risk patients had a significantly poorer LRFS compared with EP low-risk patients, which suggests that the EP assay serves as an effective tool for predicting rates of LR in luminal breast cancer patients. This result is in line with other published data demonstrating that gene profile tools correlate with both distant and LR-free survival (Mamounas et al, 2010; Arvold et al, 2011).

Mamounas et al (2010) used an expression profile tool (21-gene recurrence score) within the NSABP-B14 and NSABP-B20 trial to analyse locoregional recurrence risk (LRR). Similar to our data, high-risk lesions within the NSABP trials demonstrated increased LRR rates after 10 years $(15.8 \%$ for high-risk score $>30)$ compared with low-risk lesions $(4.3 \%<18$ score). However, no association was observed between the risk of recurrence score and LRR recurrence among women older than 50 years of age, and particularly among women over 50 who received BCT and RT. However, our data provide evidence that EP has potential prognostic significance when predicting rates of LR within patients above 50 (see Table 4). The difference between the two tests may be based on genes accounting for cell differentiation. Moreover, Mamounas et al investigated LRR including nodal recurrence, whereas the aim of our study was to investigate only ipsilateral breast recurrences. Thus, the EP test may serve as a better prognostic tool for LR. However, we caution that that EP should be further evaluated in future trials regarding tailoring local treatment.

EndoPredict and tailoring surgical therapy. The second aspect of this study was to investigate whether EP can predict the necessity of MX in postmenopausal women with breast cancer. In order to answer this question, we conducted an exploratory analysis within the subgroup of EP high-risk patients. Our data demonstrated that MX does not result in fewer LR events when compared with BCT and RT in EP high-risk patients. Similar Abdulkarim et al (2011) showed that MX did not reduce the rates of LR among patients whose breast cancer lesions were deemed to be high risk based on immunohistochemical analyses. Thus, neither immunohistochemistry nor multigenomic assays should currently be used to tailor local treatment in postmenopausal clinically low-risk breast cancer patients.

Young age is an independent factor for risk of LR after BCT and RT. Thus, it is more likely that these patients may benefit from a prognostic tool for LR in order to tailor local treatment. Data available from Mamounas et al (2010) only demonstrated that the 21 -gene recurrence score provides significant prognostic information for LRR risk in women under the age of 50. In addition, the authors failed to demonstrate that MX significantly reduced LRR rate in high-risk women under 50 years of age when compared with BCT and RT. As there were only 94 women analysed within the two NSABP trials, these questions should be explored in future trials..

EndoPredict and tailoring RT to the breast. The third question of our study pertained to administering adjuvant RT to the breast. It is well known that in $40 \%$ of patients who received BCT, cancer cells remain in the breast despite clear surgical margins (Holland et al, 1985). Thus, RT is necessary in order to reduce LR risk after BCT (Fisher et al, 2002). To date, investigations intending to find a subgroup in which adjuvant RT following BCT does not reduce risk of LR have failed (Potter et al, 2007; Hughes et al, 2013). In order to find a subgroup of low-risk patients who may not benefit from adjuvant RT, we performed an exploratory analyses of our patients after BCT with or without RT. In our analyses, EP demonstrated prognostic significance for LR only within the group of patients receiving RT. However, in women who did not receive $\mathrm{RT}$ after BCT, the LR rate was similar between the EP high- as well as EP low-risk group. Moreover, RT after BCT significantly reduced the LR rate, even in the EP low-risk group. Thus, our data provide no evidence to suggest that EP should be used to tailor RT after BCT in this clinically defined low-risk group.

Limitations of the study. No data are available regarding RT type, dosage and the use of a boost. We acknowledge the possibility that these differences could have influenced the results. Furthermore, the sample size was too small to draw any definitive conclusions. Further analyses are warranted, particularly among younger patients, as they are at an increased risk of LR (Arvold et al, 2011). In addition, several retrospective analyses suggest that MX may be more effective in mitigating risk of LR in very young women $($ age $<40)$ (van der Sangen et al, 2011).

\section{CONCLUSION}

This study demonstrates that the genetic expression profile tool EP has prognostic significance for determining LR in postmenopausal patients with endocrine-responsive her2-negative breast cancer, independent of age and nodal status. However, using EP to tailor local therapy cannot yet be recommended. Lastly, our observation of very low risk of LR in EP low-risk patients warrants further investigations to test whether RT can be omitted in such patient subgroups.

\section{ACKNOWLEDGEMENTS}

The following investigators also participated in this study: T. Bachleitner-Hofmann, S. Taucher, U. Pluschnig, R. Bartsch, G. Steger, C. Zielinski, S. Horvath, M. Seifert, C. Dadak, R. Obwegeser, E. Kubista, E. Asseryanis, R. Möslinger-Gehmayr, E. Hanzal, C. Sam (Medical University of Vienna, Vienna); P. Mayer, M. Moik, C. Menzel, B. Mlineritsch, C. Rass, R. Reitsamer, G. Russ (Salzburg Hospital, Salzburg); K. Haider, W. Kwasny, E. Markis, W. Stiglbauer (Wiener Neustadt Hospital, Wiener Neustadt); R. Grill, A. Nader, M. Stierer (Hanusch Hospital, Vienna); M. Medl, S. Redtenbacher, W. Ulrich (Hietzing Hospital, Vienna); G. Reiner (Weinviertel Hospital, Mistelbach); F. Hofbauer, M. Lang (Oberpullendorf Hospital, Oberpullendorf); W. Horvath (Güssing Hospital, Güssing); P. Kier, A. Reiner-Concin, K. Renner (Sozialmedizinisches Zentrum Ost Hospital, Vienna); P. Balcke, G. Salem, R. Sedivy (St. Pölten Hospital, St. Pölten); E. Nessler, W. Neunteufel (Dornbirn Hospital, Dornbirn); A. Haid, A. Lang, Z. Jasarevic, F. Offner (Academic Teaching Hospital Feldkirch, Feldkirch); C. Gruber, F. Kugler, G. Michlmayer, S. Pöstlberger, R. Schildberger, W. Sega (Sisters of Mercy Hospital, Linz); F. Fridrik, R. Greul, G. Hochreiner, G. Syré, C. Tausch, G. Wahl (Linz Hospital, Linz); A. Chott, H. Hartleb, H. Ludwig, H. Salzer (Wilhelminenspital, Vienna); R. Kocher, G. Leitner, F. Stangl, R. Stering, H. Rabl (Leoben Hospital, Leoben); E. Forsthuber, J. Omann, A. Urbania, K. Holzmüller, H. Rogatsch (Klagenfurt Hospital, Klagenfurt); H. Feichtinger, M. Rottmann, J. Schüller (Rudolfstiftung Hospital, Vienna); F. Burger, O. Braun (Waldviertel Hospital, Horn); G. Bayer-Tiefenbach, G. Böhm, K. Mach (Oberwart Hospital, Oberwart); B. Gebhard, W. Rausch (Vöcklabruck Hospital, 
Vöcklabruck); R. Punzengruber, W. Öhlinger (Amstetten Hospital, Amstetten); W. Döller, E. Melbinger (Wolfsberg Hospital, Wolfsberg); H. Brustmann, S. Naudé, P. Riss (Mödling Hospital, Mödling); reprints are not available from author. Sividon Diagnostic funded the development of EndoPredict. Astra Zeneca funded the prospective ABCSG 8 trial. We thank Kathryn Bouskill for English review.

\section{REFERENCES}

Abdulkarim BS, Cuartero J, Hanson J, Deschenes J, Lesniak D, Sabri S (2011) Increased risk of locoregional recurrence for women with T1-2N0 triple-negative breast cancer treated with modified radical mastectomy without adjuvant radiation therapy compared with breast-conserving therapy. J Clin Oncol 29(21): 2852-2858.

Arvold ND, Taghian AG, Niemierko A, Abi Raad RF, Sreedhara M, Nguyen PL, Bellon JR, Wong JS, Smith BL, Harris JR (2011) Age, breast cancer subtype approximation, and local recurrence after breast-conserving therapy. J Clin Oncol 29(29): 3885-3891.

Cancello G, Maisonneuve P, Rotmensz N, Viale G, Mastropasqua MG, Pruneri G, Montagna E, Dellapasqua S, Iorfida M, Cardillo A, Veronesi P, Luini A, Intra M, Gentilini O, Scarano E, Goldhirsch A, Colleoni M (2011) Prognosis in women with small (T1mic,T1a,T1b) node-negative operable breast cancer by immunohistochemically selected subtypes. Breast Cancer Res Treat 127(3): 713-720.

Dubsky P, Brase JC, Jakesz R, Rudas M, Singer CF, Greil R, Dietze O, Luisser I, Klug E, Sedivy R, Bachner M, Mayr D, Schmidt M, Gehrmann MC, Petry C, Weber KE, Fisch K, Kronenwett R, Gnant M, Filipits M (2013a) The EndoPredict score provides prognostic information on late distant metastases in ER +/HER2- breast cancer patients. Br J Cancer 109(12): 2959-2964.

Dubsky P, Filipits M, Jakesz R, Rudas M, Singer CF, Greil R, Dietze O, Luisser I, Klug E, Sedivy R, Bachner M, Mayr D, Schmidt M, Gehrmann MC, Petry C, Weber KE, Kronenwett R, Brase JC, Gnant M (2013b) EndoPredict improves the prognostic classification derived from common clinical guidelines in ER-positive, HER2-negative early breast cancer. Ann Oncol 24(3): 640-647.

Dubsky PC, Jakesz R, Mlineritsch B, Postlberger S, Samonigg H, Kwasny W, Tausch C, Stoger H, Haider K, Fitzal F, Singer CF, Stierer M, Sevelda P, Luschin-Ebengreuth G, Taucher S, Rudas M, Bartsch R, Steger GG, Greil R, Filipcic L, Gnant M (2012) Tamoxifen and anastrozole as a sequencing strategy: a randomized controlled trial in postmenopausal patients with endocrine-responsive early breast cancer from the Austrian Breast and Colorectal Cancer Study Group. J Clin Oncol 30(7): $722-728$.

Filipits M, Rudas M, Jakesz R, Dubsky P, Fitzal F, Singer CF, Dietze O, Greil R, Jelen A, Sevelda P, Freibauer C, Muller V, Janicke F, Schmidt M, Kolbl H, Rody A, Kaufmann M, Schroth W, Brauch H, Schwab M, Fritz P, Weber KE, Feder IS, Hennig G, Kronenwett R, Gehrmann M, Gnant M (2011) A new molecular predictor of distant recurrence in ER-positive, HER2-negative breast cancer adds independent information to conventional clinical risk factors. Clin Cancer Res 17(18): 6012-6020.

Fisher B, Anderson S, Bryant J, Margolese RG, Deutsch M, Fisher ER, Jeong JH, Wolmark N (2002) Twenty-year follow-up of a randomized trial comparing total mastectomy, lumpectomy, and lumpectomy plus irradiation for the treatment of invasive breast cancer. $N$ Engl J Med 347(16): 1233-1241.

Holland R, Veling SH, Mravunac M, Hendriks JH (1985) Histologic multifocality of Tis, T1-2 breast carcinomas. Implications for clinical trials of breast-conserving surgery. Cancer 56(5): 979-990.

Hughes KS, Schnaper LA, Bellon JR, Cirrincione CT, Berry DA, McCormick B, Muss HB, Smith BL, Hudis CA, Winer EP, Wood WC (2013) Lumpectomy plus tamoxifen with or without irradiation in women age 70 years or older with early breast cancer: long-term follow-up of CALGB 9343. J Clin Oncol 31(19): 2382-2387.
Jatoi I, Proschan MA (2005) Randomized trials of breast-conserving therapy versus mastectomy for primary breast cancer: a pooled analysis of updated results. Am J Clin Oncol 28(3): 289-294.

Kneubil MC, Brollo J, Botteri E, Curigliano G, Rotmensz N, Goldhirsch A, Lohsiriwat V, Manconi A, Martella S, Santillo B, Petit JY, Rietjens M (2013) Breast cancer subtype approximations and loco-regional recurrence after immediate breast reconstruction. Eur J Surg Oncol 39(3): 260-265.

Kreike B, Halfwerk H, Armstrong N, Bult P, Foekens JA, Veltkamp SC, Nuyten DS, Bartelink H, van de Vijver MJ (2009) Local recurrence after breast-conserving therapy in relation to gene expression patterns in a large series of patients. Clin Cancer Res 15(12): 4181-4190.

Mamounas EP, Tang G, Fisher B, Paik S, Shak S, Costantino JP, Watson D, Geyer Jr. CE, Wickerham DL, Wolmark N (2010) Association between the 21-gene recurrence score assay and risk of locoregional recurrence in node-negative, estrogen receptor-positive breast cancer: results from NSABP B-14 and NSABP B-20. J Clin Oncol 28(10): 1677-1683.

Millar EK, Graham PH, O’Toole SA, McNeil CM, Browne L, Morey AL, Eggleton S, Beretov J, Theocharous C, Capp A, Nasser E, Kearsley JH, Delaney G, Papadatos G, Fox C, Sutherland RL (2009) Prediction of local recurrence, distant metastases, and death after breast-conserving therapy in early-stage invasive breast cancer using a five-biomarker panel. J Clin Oncol 27(28): 4701-4708.

Pohl G, Rudas M, Taucher S, Stranzl T, Steger GG, Jakesz R, Pirker R, Filipits M (2003) Expression of cell cycle regulatory proteins in breast carcinomas before and after preoperative chemotherapy. Breast Cancer Res Treat 78(1): 97-103.

Potter R, Gnant M, Kwasny W, Tausch C, Handl-Zeller L, Pakisch B, Taucher S, Hammer J, Luschin-Ebengreuth G, Schmid M, Sedlmayer F, Stierer M, Reiner G, Kapp K, Hofbauer F, Rottenfusser A, Postlberger S, Haider K, Draxler W, Jakesz R (2007) Lumpectomy plus tamoxifen or anastrozole with or without whole breast irradiation in women with favorable early breast cancer. Int J Radiat Oncol Biol Phys 68(2): 334-340.

Reiner-Concin A, Regitnig P, Dinges HP, Hofler G, Lax S, Muller-Holzner E, Obrist P, Rudas M (2008) Practice of HER-2 immunohistochemistry in breast carcinoma in Austria. Pathol Oncol Res 14(3): 253-259.

Tanis E, van de Velde CJ, Bartelink H, van de Vijver MJ, Putter H, van der Hage JA (2012) Locoregional recurrence after breast-conserving therapy remains an independent prognostic factor even after an event free interval of 10 years in early stage breast cancer. Eur J Cancer 48(12): $1751-1756$.

Tibshirani R, Hastie T, Narasimhan B, Chu G (2002) Diagnosis of multiple cancer types by shrunken centroids of gene expression. Proc Natl Acad Sci USA 99(10): 6567-6572.

van der Sangen MJ, van de Wiel FM, Poortmans PM, Tjan-Heijnen VC, Nieuwenhuijzen GA, Roumen RM, Ernst MF, Tutein Nolthenius-Puylaert MC, Voogd AC (2011) Are breast conservation and mastectomy equally effective in the treatment of young women with early breast cancer? Longterm results of a population-based cohort of 1,451 patients aged $\leqslant 40$ years. Breast Cancer Res Treat 127(1): 207-215.

Voduc KD, Cheang MC, Tyldesley S, Gelmon K, Nielsen TO, Kennecke H (2010) Breast cancer subtypes and the risk of local and regional relapse. J Clin Oncol 28(10): 1684-1691.

Voogd AC, Nielsen M, Peterse JL, Blichert-Toft M, Bartelink H, Overgaard M, van Tienhoven G, Andersen KW, Sylvester RJ, van Dongen JA. Danish Breast Cancer Cooperative Group. Breast Cancer Cooperative Group of the European Organization for Research and Treatment of Cancer (2001) Differences in risk factors for local and distant recurrence after breastconserving therapy or mastectomy for stage I and II breast cancer: pooled results of two large European randomized trials. J Clin Oncol 19(6): 1688-1697.

This work is published under the standard license to publish agreement. After 12 months the work will become freely available and the license terms will switch to a Creative Commons AttributionNonCommercial-Share Alike 4.0 Unported License. 